\title{
STUDY ON LOW-CYCLE FATIGUE BEHAVIOR OF CAST HYBRID METAL MATRIX COMPOSITES
}

\author{
AKM Asif Iqbal ${ }^{*}$ and Yoshio Arai \\ ${ }^{1}$ Faculty of Manufacturing Engineering, Universiti Malaysia Pahang, \\ 26600 Pekan, Pahang, Malaysia \\ *Email: asifiqbal@ump.edu.my \\ Phone: +6094245935; Fax: +6094245888 \\ ${ }^{2}$ Graduate School of Science and Engineering, Saitama University, \\ 255 Shimo-okubo, Sakura-ku, Saitama-shi, Japan
}

\begin{abstract}
The low-cycle fatigue (LCF) behavior, especially the fracture initiation mechanism in a cast hybrid metal matrix composite (MMC), was studied experimentally and numerically. The conventional three-point bending fatigue test was carried out and fractographic analysis was conducted to observe the fracture initiation site. Experimental results showed that microcracks in the LCF initiated at the particle-matrix interface which was located in the hybrid clustering region. Due to continued fatigue cycling, interface debonding occurred, created additional secondary microcracks and the microcrack coalesced with other nearby microcracks. As far as the numerical study is concerned, three-dimensional (3-D) unit-cell models of the hybrid MMC consisting of reinforcement clustering and non-clustering regions were developed by using the finite element method. The stress-strain distributions in both the reinforcement clustering and non-clustering regions were analyzed. The numerical results confirmed that the stress concentration occurred on the reinforcement-matrix interface located in the clustering region and provided reasonable agreement with the experimental observations.
\end{abstract}

Keywords: Low-cycle fatigue; Cast metal matrix composites; Fracture initiation; Reinforcement clustering.

\section{INTRODUCTION}

Metal matrix composites (MMCs) make-up a category of advanced engineering materials that provide unique advantages over conventional alloys in many high performance applications. These materials have a high specific mechanical strength and a high stiffness, compared to the corresponding unreinforced alloys. Therefore, MMCs have received significant attention for automotive, aeronautical, electrical and military fields [1]. Although MMCs have many advantages, problems still remain for their poor damage tolerance properties under monotonic or cyclic loads. Many applications for which these materials can be considered involve cyclic loading, and therefore, fatigue properties are of critical interest. It has been shown that the presence of reinforcements can increase fatigue life [2]. Koh, Oh [3] investigated the low-cycle fatigue (LCF) behavior of $\mathrm{Al} / \mathrm{SiC}_{\mathrm{p}}$ composite and found that the composite and the unreinforced matrix alloy showed cyclic hardening behavior. Moreover, the fatigue endurance properties of $\mathrm{SiC}$ whisker- and particulate-reinforced composites show that the two forms of reinforcement have a similar effect; both composites are superior in high-cycle 
fatigue [2]. The improvement in the fatigue life of MMCs over conventional alloys has been ascribed to an increase in the number of cycles to initiate fatigue cracks $[2,4]$. The reinforcement helps to prevent strain localization in slip bands and thus retards slipband cracking. Chen, Lawson [1] found a high density of microcracks within a $100 \mu \mathrm{m}$ range at the reinforcement-matrix interface while studying $2124 \mathrm{Al}-20 \mathrm{vol} \% \mathrm{SiC}_{\mathrm{w}}$ reinforced composite. These microcracks initiated rapidly, at only $10 \%$ of the fatigue life, coalesced with the nearby cracks and then grew quickly to form a dominant crack leading to specimen failure. In addition, Chawla, Jones [5] observed $10 \mu \mathrm{m}$ length microcracks at the particle-matrix interface while studying $2080 \mathrm{Al} / \mathrm{SiC}_{\mathrm{p}}$ composite. While fatigue crack initiation in MMCs represents a substantial fraction of the total fatigue life, the fatigue crack growth stage can also be important. The addition of particulate reinforcement to an aluminum alloy matrix has been shown to significantly influence fatigue crack growth behavior [1, 6, 7]. Furthermore, Rafiquzzaman, Arai [8] investigated the fracture mechanism of a cast hybrid MMC under monotonic and cyclic loads. They concluded that the fracturing of the hybrid MMC under cyclic load was dominated by the interfacial debonding of the particle-matrix and whisker-matrix interfaces. It has also been reported that the main reason for fracture in discontinuously reinforced systems is the formation and coalescence of voids arising from reinforcement fracture ahead of the crack tipOh and Han [9].

These results concerning damage initiation, growth and fracture weigh in favor of either particulate- or whisker-reinforced MMCs. The experimental and numerical analysis for a cast hybrid MMC is rare. At present, studies of cast hybrid MMCs are limited to the investigation of fracture mechanisms and wear properties $[8,10]$. A detailed understanding of the LCF behavior of cast hybrid MMCs is required for an extension of their application in industry, in particular when large deformations are unavoidable. The experimental and numerical study of the LCF behavior, especially the damage nucleation and fracture mechanism of a cast hybrid MMC reinforced with $\mathrm{SiC}$ particles and $\mathrm{Al}_{2} \mathrm{O}_{3}$ whiskers, is presented here. Fractographic analysis was used to explain the microcrack initiation in LCF. A three-dimensional (3-D) unit-cell model in the periodic boundary condition was developed by using the finite element method (FEM) to analyze the stress distribution in the reinforcement and matrix which could lead to microcrack initiation in cast hybrid MMCs.

\section{MATERIALS AND EXPERIMENTAL METHODS}

The material used for the study is cast hybrid MMC. The material was fabricated with aluminum alloy JIS-AC4CH as the matrix and $21 \mathrm{vol} \% \mathrm{SiC}$ particles and $9 \mathrm{vol} \% \mathrm{Al}_{2} \mathrm{O}_{3}$ whiskers as the reinforcements. The squeeze casting process was used to fabricate the material. A hybrid preform of $\mathrm{SiC}$ particles and $\mathrm{Al}_{2} \mathrm{O}_{3}$ whiskers was made and $100 \mathrm{MPa}$ maximum casting pressure was applied throughout the process as this was adequate to overcome the resistance against flow and to press the melt into all the open pores of the hybrid preform. The materials were heat treated by the $\mathrm{T} 7$ process. The chemical composition of AC4CH alloy is listed in Table 1.

Table 1. Chemical composition of AC4CH alloy (wt.\%)

\begin{tabular}{lllll}
\hline $\mathrm{Si}$ & $\mathrm{Fe}$ & $\mathrm{Mg}$ & $\mathrm{Ti}$ & $\mathrm{Al}$ \\
\hline 7.99 & 0.2 & 0.57 & 0.07 & $\mathrm{Bal}$. \\
\hline
\end{tabular}




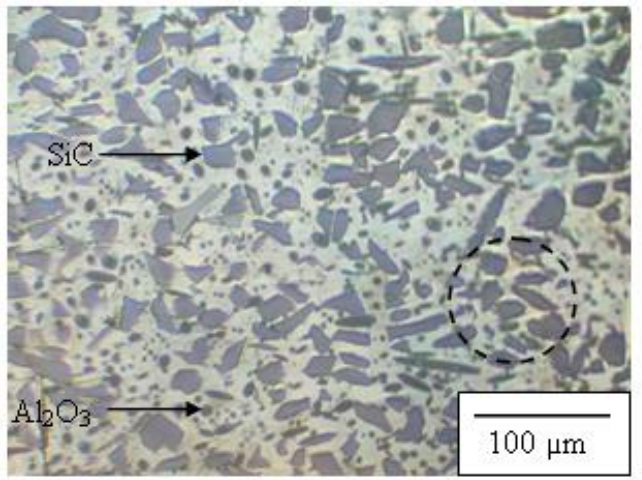

(a)

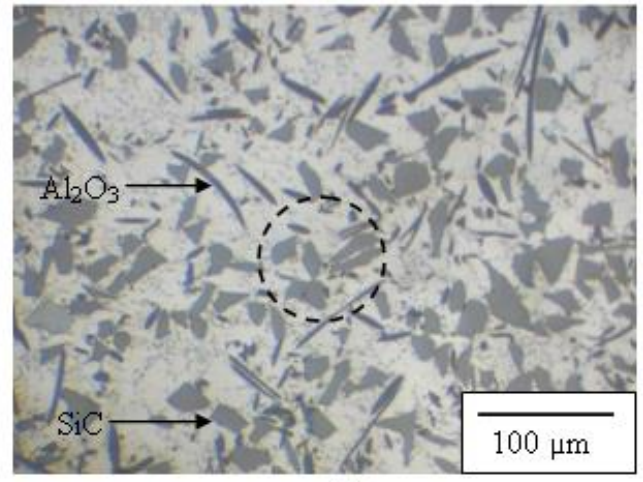

(b)

Figure 1. Microstructure of the hybrid MMC in (a) a lateral and (b) a longitudinal cross section.

Table 2. Mechanical properties of reinforcement and tested materials

\begin{tabular}{lllll}
\hline Parameters & $\mathrm{Al}_{2} \mathrm{O}_{3}$ & $\mathrm{SiC}$ & $\mathrm{Al}$ alloy AC4CH & Hybrid MMC \\
\hline Young's modulus [11] & 380 & 450 & 70.0 & 142 \\
Poisson's ratio & 0.27 & 0.20 & 0.33 & 0.28 \\
Yield strength (MPa) & - & - & 131 & 166 \\
Tensile strength (MPa) & - & - & 262 & 228 \\
Tensile elongation (\%) & & & 9.22 & 2.77 \\
\hline
\end{tabular}

As described in the previous report [12], owing to the formation process of the preform the whiskers in the hybrid MMC are randomly oriented in a plane. In this article, "longitudinal cross section" is defined as the plane and "lateral cross section" is defined as that perpendicular to the plane. Figure 1 shows the lateral and longitudinal microstructures of the hybrid MMC. The $\mathrm{SiC}$ particles in the hybrid MMC were mostly rectangular with sharp corners (Figure $1 \mathrm{a}, \mathrm{b}$ ), and most of the $\mathrm{Al}_{2} \mathrm{O}_{3}$ whiskers were roller-shaped (Figure 1a, b). The average length of $\mathrm{SiC}$ particles and the $\mathrm{Al}_{2} \mathrm{O}_{3}$ whiskers was $23 \mu \mathrm{m}$ and $35 \mu \mathrm{m}$, respectively. The average diameter of the $\mathrm{Al}_{2} \mathrm{O}_{3}$ whiskers was 2 $\mu \mathrm{m}$. The $\mathrm{Al}_{2} \mathrm{O}_{3}$ whiskers were randomly oriented in the same plane as the longitudinal cross section of the specimen. Clusters of $\mathrm{SiC}$ particles and $\mathrm{Al}_{2} \mathrm{O}_{3}$ whiskers were observed at frequent intervals in the hybrid MMC as indicated by the broken lines in Figure 1(a) and 1(b), respectively. The local volume fraction of the reinforcement in the clustering region was found to be $60 \%$. The mechanical properties of reinforcement materials and hybrid MMC are shown in Table 2. The listed properties for the hybrid MMC are along the direction in the longitudinal cross section. Conventional three-point bending tests were carried out on rectangular bar smooth specimens to reduce the observation area of crack initiation. The specimen dimensions were as follows: length of $100 \mathrm{~mm}$, thickness of $6 \mathrm{~mm}$ and width of $8 \mathrm{~mm}$. The machined surfaces of the specimens were polished by using a polishing machine sequentially using 15,3 , and 1 $\mu \mathrm{m}$ diamond particles until all scratches and surface machining marks were removed. Three-point bending tests were performed using special bending fixtures equipped with a $5 \mathrm{kN}$ load cell in a Shimazu ServoPulser. The span distance was $60 \mathrm{~mm}$. Load and deflection data were recorded by a computer data acquisition system. First, the monotonic bending tests were conducted at a displacement rate of $0.0025 \mathrm{~mm} \cdot \mathrm{s}-1$. The strength of the hybrid MMC was calculated from the maximum load at failure as a 
nominal bend stress $\sigma_{\mathrm{c}}=386 \mathrm{MPa}$ as shown in Figure 2. Cyclic fatigue tests were conducted in the load control mode under the load ratio $R=0.1$ at a frequency of 0.5 Hz. Three specimens of hybrid MMC which are mentioned in this article, TP-1, TP-2 and TP-3, were tested with the maximum stresses of $0.7 \sigma_{\mathrm{c}}, 0.8 \sigma_{\mathrm{c}}$, and $0.9 \sigma_{\mathrm{c}}$. The maximum stress used for each test specimen is shown in Table 3. All tests were carried out at room temperature. The number of cycles to failure was considered as the fatigue life $N_{f}$. To observe the initiation and growth of microcracks, the plastic replica technique was used at various times during the fatigue life. During replication, the specimen was held at mean load to ensure that any cracks that might be present would be fully opened. Replicas were taken using Bioden replicating films softened in acetone. Finally, an optical microscope was used to examine the replicas. Prior to testing, no cracks were seen. In this article, "crack initiation" is defined as the point at which a black line of several micrometers is first observed in the magnified replica image, during the cyclic loading test. The tensile and fracture surfaces were comprehensively examined using scanning electron microscopy (SEM) and energy-dispersive x-ray spectroscopy (EDS) to characterize the crack initiation site.

\section{RESULTS AND DISCUSSION}

Figure 3 shows the optical micrographs of replicas obtained at various stages of LCF testing of the hybrid MMC specimen TP-3. This figure represents the initiation of microcracks and their growth to final failure during LCF. For TP-3, at $11 \%$ of the fatigue life, several cracks of around $15-25 \mu \mathrm{m}$ in length were initiated at the specimen surface (indicated by arrows in Figure 3(a)). These cracks then coalesced together, and at $30 \%$ of the fatigue life, the crack extended to $120 \mu \mathrm{m}$ in length (Figure 3(b)). At $55 \%$ of the fatigue life, the crack further extended to $230 \mu \mathrm{m}$ (Figure 3(c)). Moreover, a few cracks of $15-25 \mu \mathrm{m}$ in length were also formed ahead of the main crack tip at this stage (arrows in Figure 3(c)). At 90\% of the fatigue life, all of these cracks coalesced and a fatal crack was produced (Figure 3(d)). The size of the fatal crack was around $550 \mu \mathrm{m}$ on the specimen surface. The final failure took place at 524 cycles. Similar phenomena were observed in specimens TP-1 and TP-2.

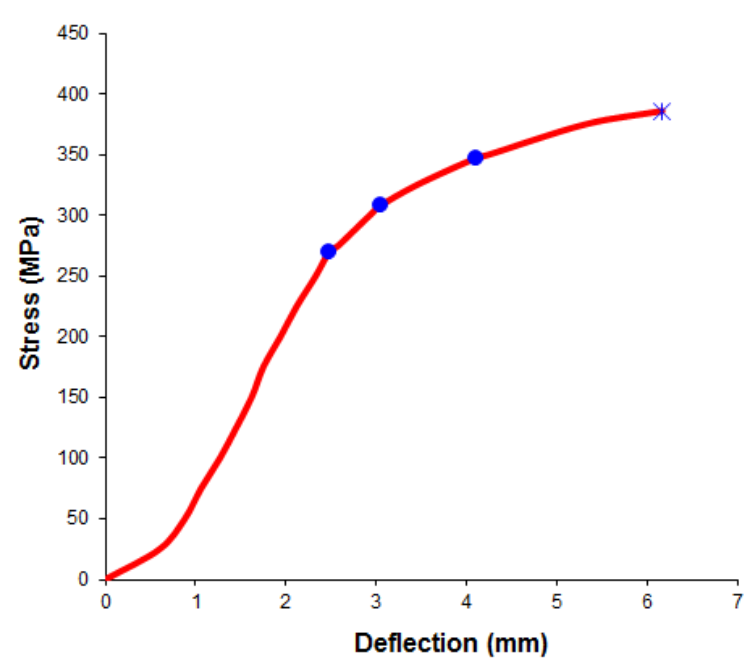

Figure 2. Nominal stress Vs deflection curve of hybrid MMC under monotonic loading. Table 3. Maximum stress used on the specimens. 


\begin{tabular}{ll}
\hline Specimen & Peak stress used $(\mathrm{MPa})$ \\
\hline TP-1 & 270 \\
TP-2 & 308 \\
TP-3 & 347 \\
\hline
\end{tabular}

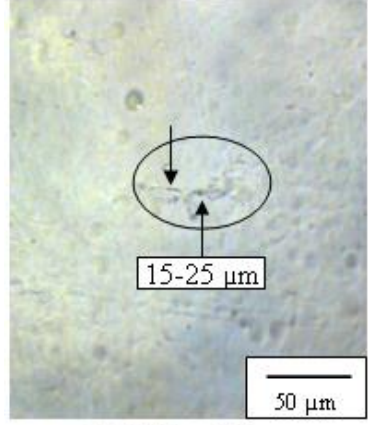

(a) $\mathrm{N}_{1} / \mathrm{N}_{\mathrm{f}}=0.11$

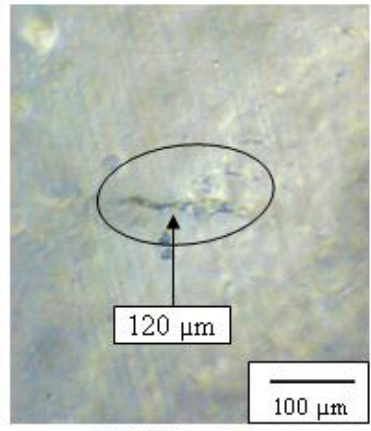

(b) $\mathrm{N}_{1} / \mathrm{N}_{\mathrm{f}}=0.3$

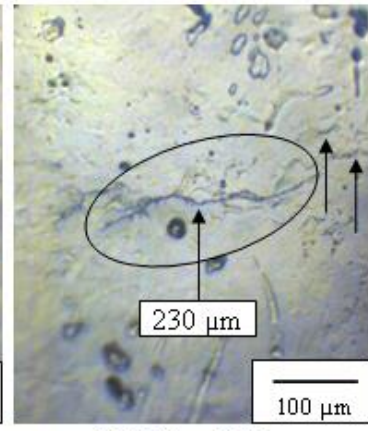

(c) $\mathrm{N}_{1} / \mathrm{N}_{\mathrm{f}}=0.55$

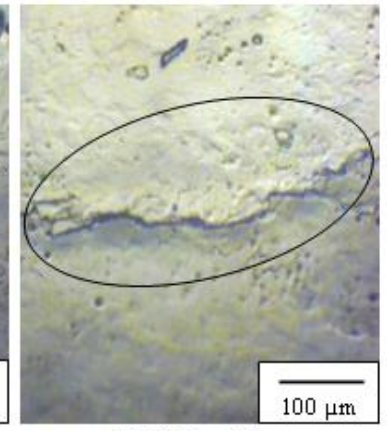

(d) $\mathrm{N}_{1} / \mathrm{N}_{\mathrm{f}}=0.9$

Figure 3. Fatigue crack initiation and propagation in hybrid MMC: $\sigma_{\mathrm{c}}=347 \mathrm{MPa}, N_{f}=$ 524 cycles.

Figure 4 shows the crack initiation site at the matching tensile surface of the fractured specimen TP-3. This optical micrograph shows that the microcracks in the hybrid MMC initiated at the particle-matrix interface (as indicated by the "Particle 1 " and the "Matrix ${ }_{1}$ " arrows in Figure 4 which correspond to the microcracks in Figure 3(a)). The crack initiated $\mathrm{SiC}$ particle was located in the hybrid clustering region of the $\mathrm{SiC}$ particles and $\mathrm{Al}_{2} \mathrm{O}_{3}$ whiskers (as indicated by the circle in Figure 4). Few $\mathrm{Al}_{2} \mathrm{O}_{3}$ whiskers were found located very close to the crack initiated SiC particle (as indicated by the "Whisker" arrows in Figure 4). Therefore, it is clear from the optical micrograph that crack initiation occurred in the hybrid clustering region of the hybrid MMC where both $\mathrm{SiC}$ particles and $\mathrm{Al}_{2} \mathrm{O}_{3}$ whiskers exist very close to one another. Figure 5 shows the SEM and EDS images of the matching fracture surfaces of the microcrack initiation site in the hybrid MMC during LCF. The area indicated by $P_{1}$ in Figure 5(a) corresponds to the location indicated by the "Particle," arrow in Figure 4, and the area $M_{1}$ in Figure 5(a) corresponds to the location indicated by the "Matrix ${ }_{1}$ " arrow in Figure 4. Figure 5(b) shows the EDS mapping analysis results in the areas corresponding to Figure 5(a). The presence of $\mathrm{Al}, \mathrm{Si}$, and $\mathrm{O}$ on the fracture surfaces is indicated by the green, blue, and red colors respectively in Figure 5(b). The blue area indicated by $P_{1}$ in Figure 5(b) contains a significant amount of Si (88\%) and a small amount of $\mathrm{Al}(12 \%)$, identifying the area as an $\mathrm{SiC}$ particle (corresponding to $P_{1}$ in Figure 5(a)). The green area indicated by $M_{l}$ contains a large amount of $\mathrm{Al}(91 \%)$ and a small amount of $\mathrm{Si}(9 \%)$, indicating that this area is an $\mathrm{Al}$ matrix (corresponding to $M_{1}$ in Figure 5(a)). Therefore, the blue and green areas indicated by the $P_{1}-M_{1}$ pair in the matching halves denote the crack initiation site in the hybrid clustering region of $\mathrm{SiC}$ particles and $\mathrm{Al}_{2} \mathrm{O}_{3}$ whiskers (Figure 3(a)) where $\mathrm{SiC}$ particle-matrix interfacial debonding occurred. The blue $P_{2}-P_{2}$ pair in Figure 5(b) indicates the presence of SiC particles on both sides of the fractured surface, meaning that interface debonding was followed by transgranular fracturing in this clustering region (corresponding to the $P_{2^{-}}$ $P_{2}$ pair in Figure 5(a)). 


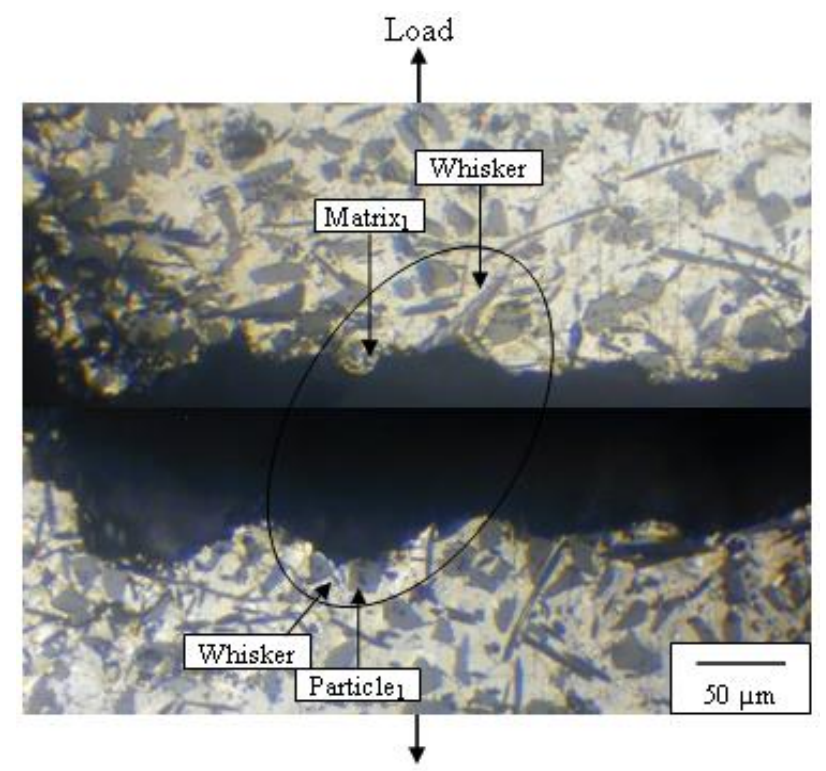

Figure 4. Optical micrograph of the crack initiation site in the hybrid MMC.

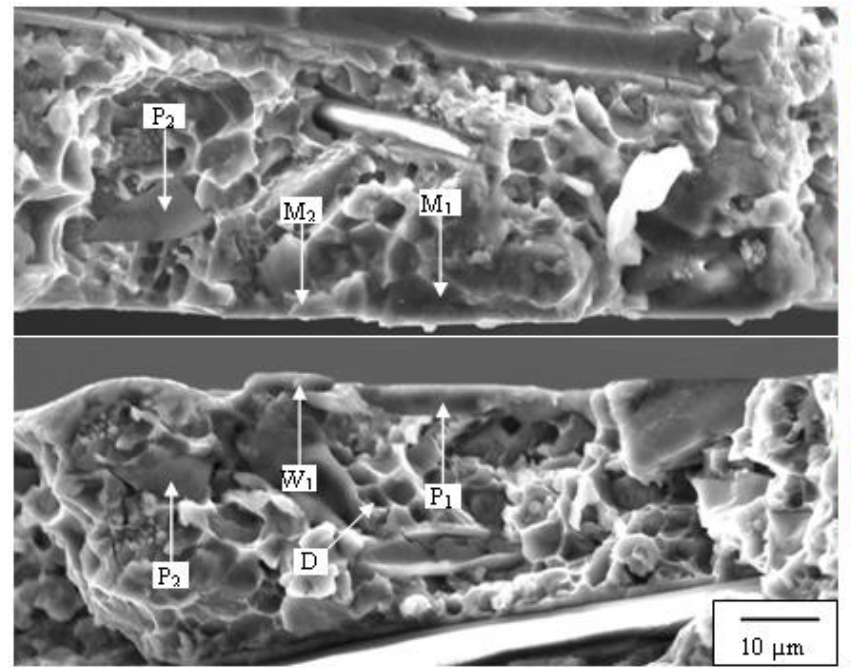

(a)

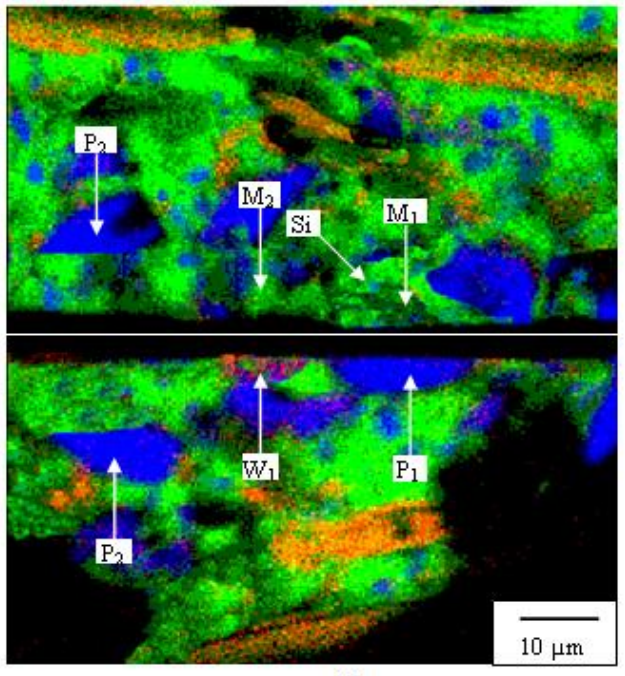

(b)

Figure 5. Crack initiation site in the hybrid MMC: (a) SEM micrograph, (b) EDS mapping analysis.

The coexistence of green and red, indicating the presence of both $\mathrm{Al}$ and $\mathrm{O}$, identifies this area as an $\mathrm{Al}_{2} \mathrm{O}_{3}$ whisker, denoted by $W_{1}$ in Figure 5(b) (corresponding to $W_{1}$ in Figure 5(a)). This $\mathrm{Al}_{2} \mathrm{O}_{3}$ whisker was located very close to the debonded $\mathrm{SiC}$ particle. Interfacial debonding was also found in this $\mathrm{Al}_{2} \mathrm{O}_{3}$ whisker, as indicated by the $W_{1}-M_{2}$ pair in Figure 5(b) (corresponding to the $W_{1}-M_{2}$ pair in Figure 5(a)). A number of dimples were nucleated (indicated by the $D$ arrows in Figure 5(a)) in the aluminum alloy matrix. The EDS mapping analysis confirmed the presence of a few Si particles on the opposite side of the dimples (as indicated by the Si arrow in Figure 5(b)). Dimple formation indicated the occurrence of void nucleation, which was induced by plastic deformation of the Al matrix at the second phase Si particles. However, the edge of the dimples was not as clear as those in the unstable fracture region, likely due to the 
mutual contact effect due to cyclic loading. Similar observations were made for the fracture surface of the other specimens.

The above observations clearly demonstrate the LCF effect on the microcrack initiation mechanism in hybrid MMCs. Microcracks were always initiated due to the debonding of the particle-matrix interfaces located in the hybrid clustering region where $\mathrm{SiC}$ particles and $\mathrm{Al}_{2} \mathrm{O}_{3}$ whiskers exist very close to one another. Previous researchers stated that debonding at the reinforcement-matrix interface is the main reason for microcrack initiation in the particulate- or whisker-reinforced system $[1,5$, 6]. The results obtained for hybrid MMCs are consistent with these observations. Moreover, in the hybrid clustering region where the $\mathrm{SiC}$ particles and $\mathrm{Al}_{2} \mathrm{O}_{3}$ whiskers are present in very close proximity, the hybridization effect occurs which reduces the crack initiation resistance in hybrid MMCs. This hybridization effect may occur due to the elastic-plastic interaction between the reinforcing particles, whiskers and matrix during LCF. Therefore, to understand the characteristics of the elastic-plastic stress fields and hybridization effect, a numerical analysis is carried out on the reinforcing particles, whiskers and matrix in the clustering and non-clustering regions, as described in the following section.

\section{Numerical Model}

To characterize the hybridization effect on stress distribution in hybrid MMC during LCF, 3-D unit-cell models using FEM were developed. ABAQUS software [13] was used for the calculation. The models consist of whiskers and particles in random orientation. The schematic illustrations and finite element mesh of the models are shown in Figures 6 and 7, respectively. In Model-1 (Figure 6), particles are located around a whisker, showing the hybrid clustering of the reinforcement, whereas, Model-2 (Figure 7) includes a particle and a whisker which are located side by side representing the non-clustering region of the hybrid MMC. In this numerical analysis, it is assumed that the whiskers are rectangular in shape of length 1 and width $\mathrm{d}$, and the particles are the cubic shape of length $b$ respectively. Only $1 / 8$ of one unit cell is treated because of the symmetry of the cell. The reinforcement volume fraction of Model-1 is kept at 58 vol\% as the local volume fraction of the reinforcements usually increases in the hybrid clustering region, as shown in Figure 1. On the other hand, for Model-2, the reinforcement volume fraction is modeled as the real microstructure of the hybrid MMC of $9 \mathrm{vol} \% \mathrm{Al}_{2} \mathrm{O}_{3}$ whiskers and $21 \mathrm{vol} \% \mathrm{SiC}$ particles in an $\mathrm{Al}$ alloy matrix. The size of the model is determined by the following formulae: $b^{3} / \mathrm{LH}^{2}=\mathrm{V}_{\mathrm{p}}$ (for cubic shaped particles) and $\mathrm{ld}^{2} / \mathrm{LH}^{2}=\mathrm{V}_{\mathrm{w}}$ (for whiskers), where, $\mathrm{V}_{\mathrm{p}}$ and $\mathrm{V}_{\mathrm{w}}$ are the particle and whisker volume fractions, respectively. The $\mathrm{SiC}$ particles and $\mathrm{Al}_{2} \mathrm{O}_{3}$ whiskers are modeled as linear elastic, characterized by Young's modulus $\mathrm{E}_{\mathrm{p}}=450 \mathrm{GPa}$ and Poisson's ratio $v_{\mathrm{p}}=0.2$ for SiC particles, and Young's modulus $\mathrm{E}_{\mathrm{w}}=380 \mathrm{GPa}$ and Poisson's ratio $v_{\mathrm{w}}=0.27$ for $\mathrm{Al}_{2} \mathrm{O}_{3}$ whiskers. The behavior of $\mathrm{Al}$ alloy matrix is modeled as an isotropic elastic-plastic response, with Young's modulus $\mathrm{E}_{\mathrm{Al}}=70 \mathrm{GPa}$ and Poisson's ratio $v_{\mathrm{Al}}=0.33$. The symmetric boundary condition is applied to the $\mathrm{Y}-\mathrm{Z}$ plane at the left, $\mathrm{X}-\mathrm{Y}$ plane at the front and $X-Z$ plane at the top of the models. Moreover, the periodic boundary condition is applied to the $\mathrm{X}-\mathrm{Z}$ plane at the bottom and $\mathrm{X}-\mathrm{Y}$ plane at the back of all the models. A uniform displacement of $0.05 \mu \mathrm{m}$ for the half length of the unit cell, $20 \mu \mathrm{m}$ is applied to the $\mathrm{Y}-\mathrm{Z}$ plane at the right of all the models, which corresponds to a $347 \mathrm{MPa}$ nominal stress for the hybrid MMC. 

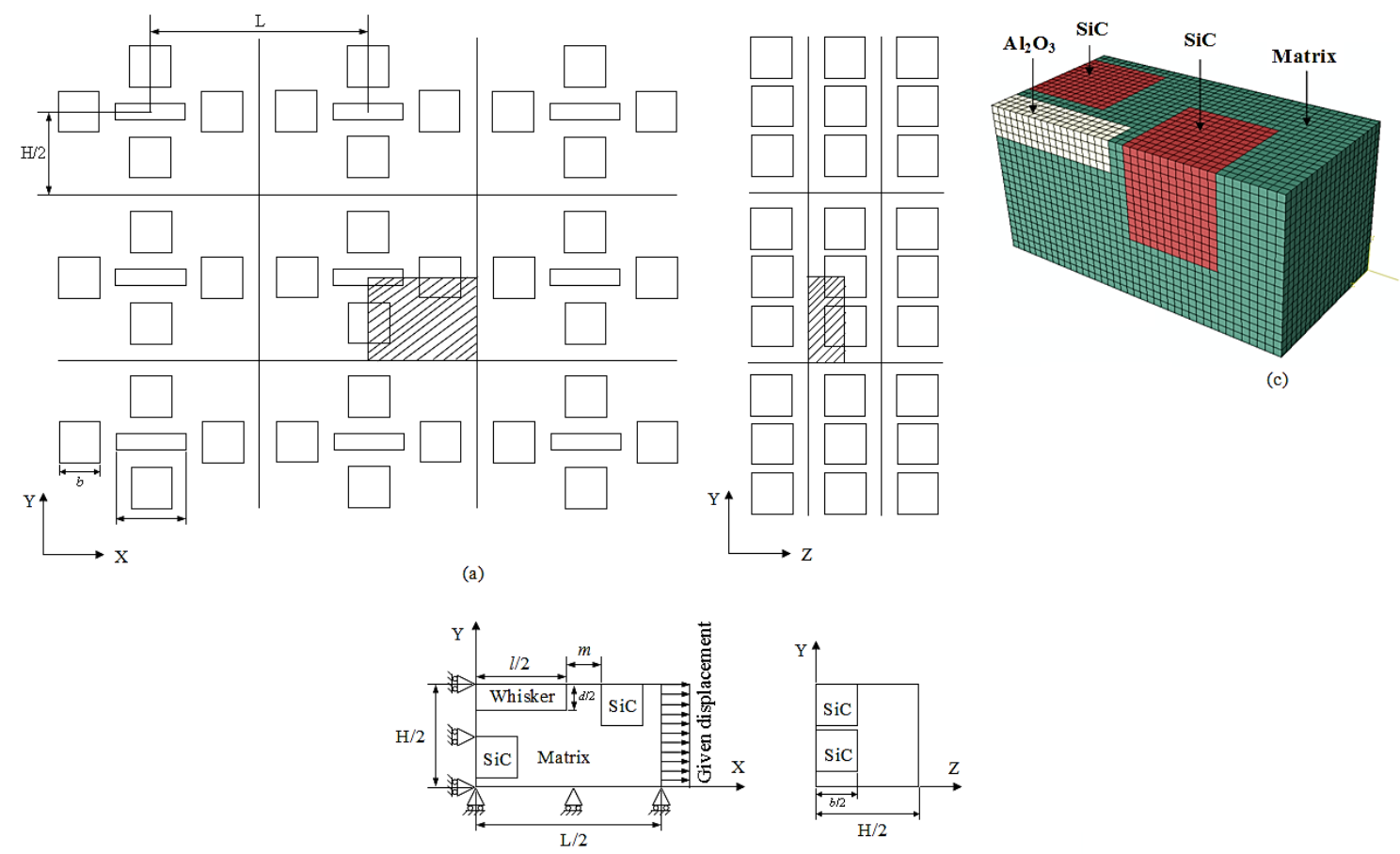

(b)
Model-1

Figure 6. Model-1 representing the hybrid clustering region in the hybrid MMC:

(a) schematic illustration of the periodic particle and whisker arrangement (b) 1/8 of one unit cell, analysis based on symmetry (c) finite element mesh.
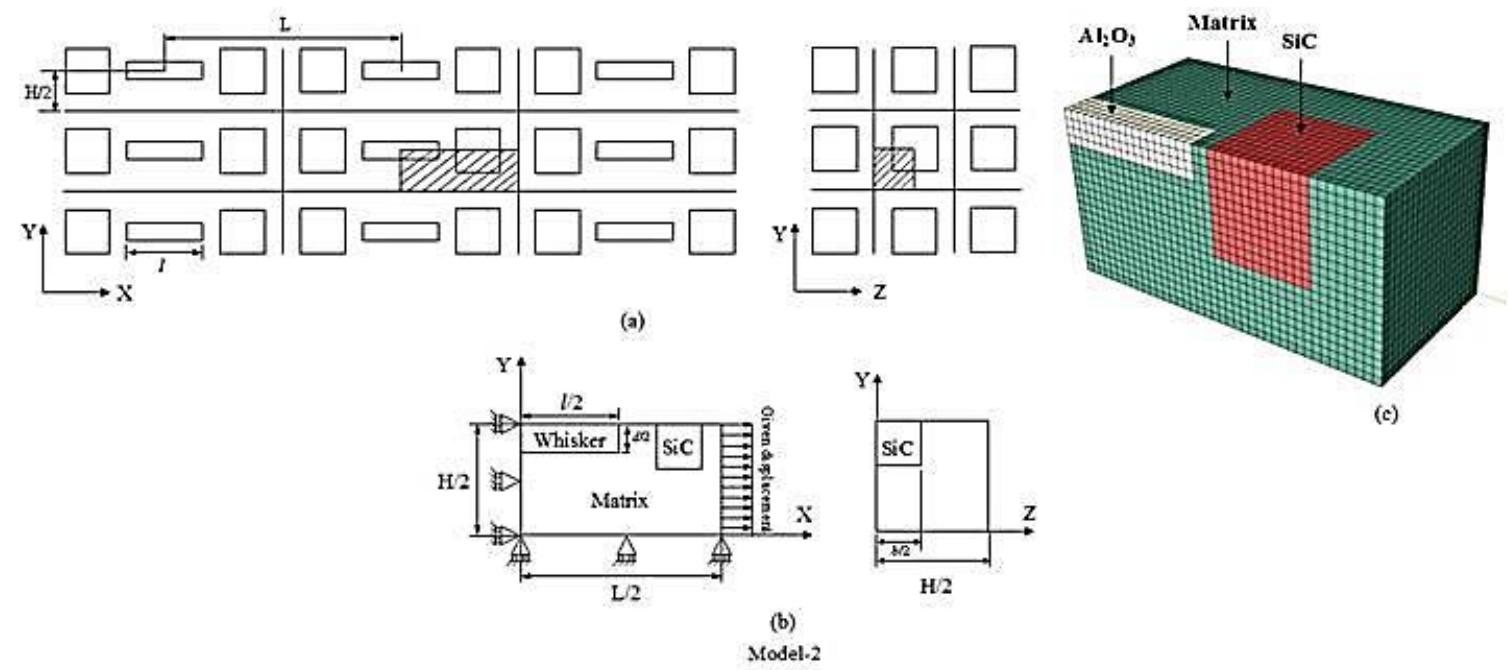

Figure 7. Model-2 representing the non-clustering region in the hybrid MMC:

(a) schematic illustration of the periodic particle and whisker arrangement (b) 1/8 of one unit cell, analysis based on symmetry (c) finite element mesh.

\section{Numerical Analysis}

In order to study the LCF effect on the fracture initiation mechanism in the hybrid MMC, the stress and strain fields are highlighted in Figure 8. Figures 8(a) and 8(b) represent the von Mises effective stress in the reinforcement clustering and non- 
clustering regions. Apparently, the von Mises effective stress in the reinforcement clustering region can be found to be much higher than that of the non-clustering region. The $\mathrm{Al}_{2} \mathrm{O}_{3}$ whiskers experience higher stress in both the regions as compared to the stress developed on the $\mathrm{SiC}$ particles and the $\mathrm{Al}$ alloy matrix. However, the maximum von Mises effective stress in the matrix is located at the tip of the particles and whiskers. This is attributed to the stress concentration in the vicinity of the reinforcement. Moreover, it can be seen that the von Mises effective stress in the SiC particle is greater than that in the matrix, which shows the obvious strengthening effect. The contour plots of the equivalent plastic strain in the clustering and non-clustering regions are shown in Figures 8(c) and 8(d), respectively. It can be seen that there is a great plastic strain gradient in the matrix in both the regions. However, the plastic strain in the clustering region is much higher than that in the non-clustering region. It can also be understood that the plastic flow initiates in the matrix at the particle tip along the loading direction. The comparison of the maximum von Mises effective stress developed on the $\mathrm{Al}_{2} \mathrm{O}_{3}$ whisker, $\mathrm{SiC}$ particles and the $\mathrm{Al}$ alloy matrix are shown in Figure 9(a). It is noteworthy that the maximum von Mises effective stress in the $\mathrm{Al}_{2} \mathrm{O}_{3}$ whisker and $\mathrm{SiC}$ particle is $759 \mathrm{MPa}$ and $521 \mathrm{MPa}$, respectively, in the reinforcement clustering region and they are clearly higher than the maximum von Mises effective stress of $550 \mathrm{MPa}$ and $400 \mathrm{MPa}$ in the $\mathrm{Al}_{2} \mathrm{O}_{3}$ whisker and $\mathrm{SiC}$ particle, respectively, in the non-clustering region.
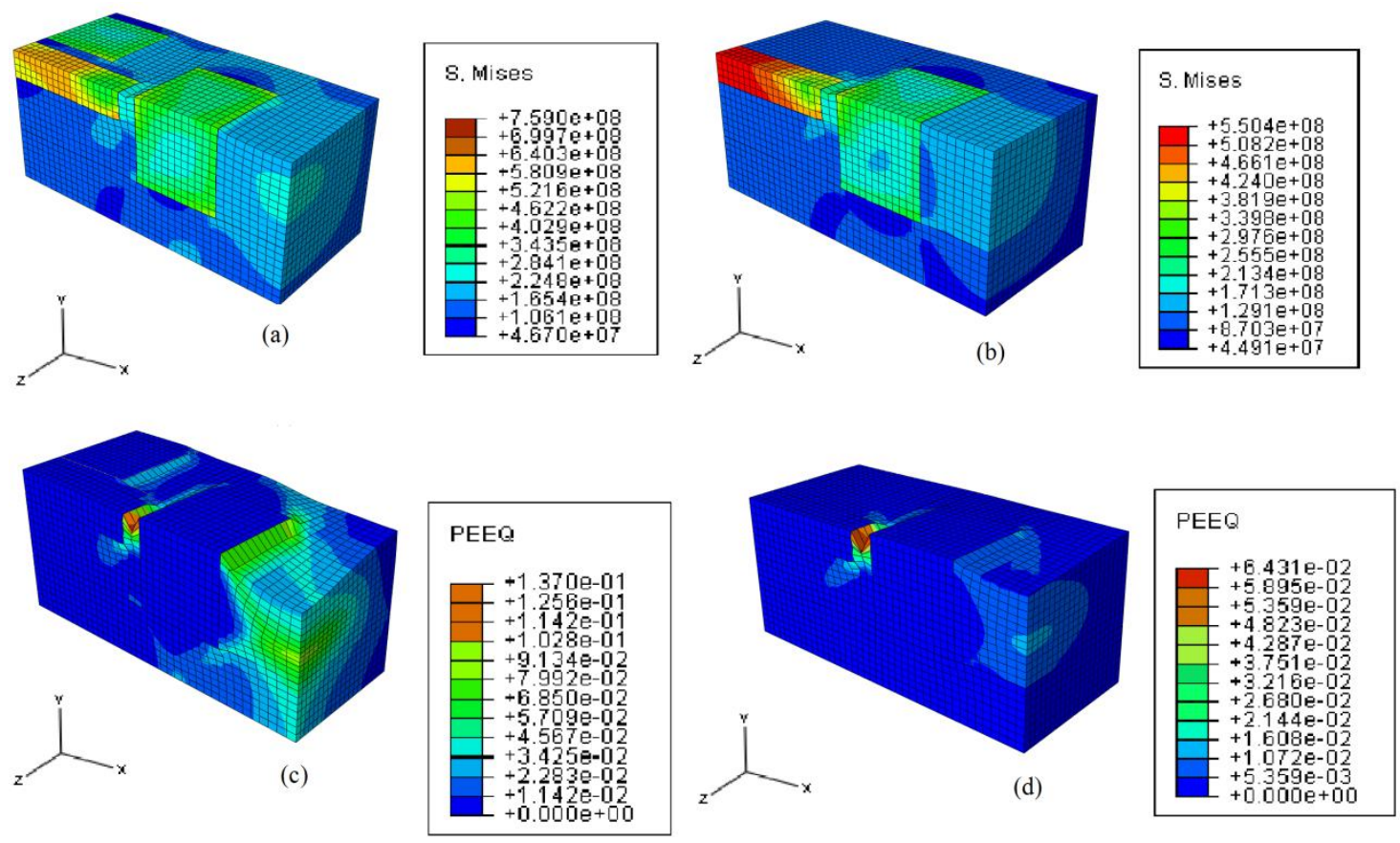

Figure 8. Numerical results: (a) von Mises effective stress in the hybrid clustering region, (b) von Mises effective stress in the non-clustering region, (c) equivalent plastic strain in the hybrid clustering region, (d) equivalent plastic strain in the non-clustering region.

Additionally, the Al alloy matrix has maximum von Mises effective stress of $326 \mathrm{MPa}$ in the reinforcement clustering region, which is higher than the maximum von Mises effective stress of $280 \mathrm{MPa}$ in the non-clustering region. From the maximum von Mises effective stress values, it is concluded that the stress gradient increases in the 
clustering region and the mechanical response of the hybrid MMC is sensitive to the reinforcement distribution. Figure 9(b) represents the variation in the maximum equivalent plastic strain in the $\mathrm{Al}$ matrix at both the clustering and non-clustering regions. The maximum strain of 0.137 was observed in the $\mathrm{Al}$ matrix between the $\mathrm{Al}_{2} \mathrm{O}_{3}$ whisker and $\mathrm{SiC}$ particle in the clustering region, which is much higher than the maximum plastic strain of 0.064 in the non-clustering region. From the above numerical results the LCF effect on the fracture initiation mechanism can be clearly understood. It is evident that the reinforcements located in the clustering region experience higher stress than the non-clustering region and stress concentration in the matrix occurs in the vicinity of the reinforcement during LCF. Moreover, the plastic strain is higher in the matrix at the clustering region, which localizes between the particles and the whiskers. On the contrary, no plastic strain is observed in the reinforcement particles and whiskers that lead to large strain mismatch between the reinforcing materials and the Al alloy matrix. Due to this large mismatch of strain, cracks initiate at the particle-matrix interface, located in the cluster of reinforcements in the hybrid MMC during LCF.

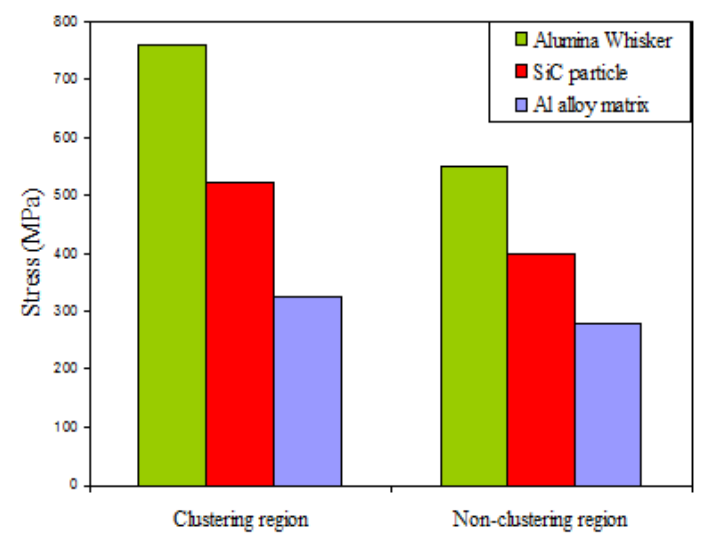

(a)

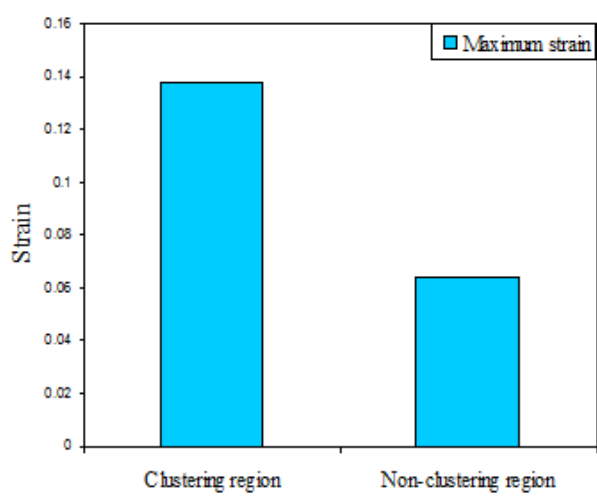

(b)

Figure 9. Comparison of (a) the maximum stress developed in the clustering and nonclustering regions, (b) the maximum strain developed in the matrix in the clustering and non-clustering regions.

\section{CONCLUSIONS}

The LCF behavior, especially the fracture initiation mechanism in the cast hybrid MMC during LCF, was investigated experimentally and numerically. The following conclusions were made:

(1) In the cast hybrid MMC, fracturing due to LCF initiated at the particle-matrix interface which was located in the hybrid clustering region. Due to continued fatigue cycling, the interface was debonded in the fracture, additional secondary microcracks were created and the microcrack coalesced with other nearby microcracks.

(2) The numerical results confirmed that the reinforcements located in the clustering region experienced higher stresses compared to those in the non-clustering region. The stress concentration occurred on the reinforcement-matrix interfaces 
located in the clustering region and this region is found to be highly vulnerable to initiating fractures in cast hybrid MMCs during LCF.

\section{ACKNOWLEDGMENTS}

The authors express gratitude to the Ministry of Education, Science, Sports and Culture of the Government of Japan for providing financial support during this research work.

\section{REFERENCES}

[1] Chen E, Lawson L, Meshii M. The effect of fatigue microcracks on rapid catastrophic failure in $\mathrm{Al} \square \mathrm{SiC}$ composites. Materials Science and Engineering: A. 1995;200:192-206.

[2] Sasaki M, Lawson L, Meshii M. Low-cycle fatigue properties of a SiC whiskerreinforced 2124 aluminum alloy. Metallurgical and Materials Transactions A. 1994;25:2265-74.

[3] Koh S, Oh S, Li C, Ellyin F. Low-cycle fatigue life of SiC-particulate-reinforced Al-Si cast alloy composites with tensile mean strain effects. International journal of Fatigue. 1999;21:1019-32.

[4] Davidson DL. The effect of particulate $\mathrm{SiC}$ on fatigue crack growth in a castextruded aluminum alloy composite. Metallurgical Transactions A. 1991;22:97112.

[5] Chawla N, Jones J, Andres C, Allison J. Effect of SiC volume fraction and particle size on the fatigue resistance of a $2080 \mathrm{Al} / \mathrm{SiC} \mathrm{p}$ composite. Metallurgical and Materials Transactions A. 1998;29:2843-54.

[6] Chen Z, Tokaji K. Effects of particle size on fatigue crack initiation and small crack growth in $\mathrm{SiC}$ particulate-reinforced aluminium alloy composites. Materials Letters. 2004;58:2314-21.

[7] Chawla N, Ganesh V. Fatigue crack growth of SiC particle reinforced metal matrix composites. International Journal of Fatigue. 2010;32:856-63.

[8] Rafiquzzaman M, Arai Y, Tsuchida E. Fracture mechanisms of aluminium cast alloy locally reinforced by $\mathrm{SiC}$ particles and $\mathrm{Al} 2 \mathrm{O} 3$ whiskers under monotonic and cyclic load. Materials Science and Technology. 2008;24:273-80.

[9] Oh K, Han K. Short-fiber/particle hybrid reinforcement: Effects on fracture toughness and fatigue crack growth of metal matrix composites. Compos Sci Technol. 2007;67:1719-26.

[10] Fu HH, Han KS, Song JI. Wear properties of Saffil/Al, Saffil/Al 2 O 3/Al and Saffil/SiC/Al hybrid metal matrix composites. Wear. 2004;256:705-13.

[11] Eitssayeam S, Intatha U, Rujijanagul G, Pengpat K, Tunkasiri T. Structural and electrical properties characterization of $(1-\mathrm{x}) \mathrm{PbZr} 0$. 52Ti0. 48O3-xBaFe0. 5Nb0. $5 \mathrm{O} 3$ system. Applied Physics A. 2006;83:295-9.

[12] Iqbal AA, Arai Y, Araki W. Effect of hybrid reinforcement on crack initiation and early propagation mechanisms in cast metal matrix composites during low cycle fatigue. Materials \& Design. 2013;45:241-52.

[13] Systèmes D. ABAQUS User's Manual. version; 2009. 